Dialogic Essentialism and Protecting Against Stigma within the Fat Admirer Community

Elyse Neumann

1415 Jayhawk Blvd, Rm 709, Lawrence, KS, 66046

Department of Sociology, The University of Kansas, Lawrence, The United States

Email: eneumann@ku.edu

Elyse Neumann is a PhD student at the University of Kansas. Her work involves fat studies, gender, and Medical Sociology. 


\title{
Dialogic Essentialism and Protecting Against Stigma within the Fat Admirer Community
}

\begin{abstract}
Fat Admirers (FAs) represent a group of stigmatized individuals who challenge Western ideals of beauty. Using an internet ethnography, I analyze the sharing of stigmatizing experiences among FAs on the Dimensions forum, an online community for FAs and FFAs (female Fat Admirers). This research explains how individuals shape their understanding of an FA identity and how the use of self-protective strategies promote increased importance, validation, and protection of a stigmatized identity. This research adds to previous work on selfprotective strategies against stigma. I argue that a new strategy, dialogic essentialism, is employed. Dialogic essentialism describes the process by which FAs converse with similarly situated others in attempts to normalize their essentialist beliefs, thus protecting against possible stigmatization.
\end{abstract}

Keywords: Fat Admirers, Stigma, Self-Protective Strategies, Internet Ethnography

\section{Introduction}

Fat individuals in Western societies experience stigma and discrimination in their everyday lives (Puhl and Brownell 2001; 2006), yet there exists communities of individuals who accept and admire fatness. Members of the Fat Admirer community engage in public participation of fat admiration via compulsory thin desire, systems of attraction that dictate thin sexual partners as a normative ideal. Compulsory thin desire derives from McRuer's (2014) concept of compulsory able-bodiedness and Rich's (1980) compulsory heterosexuality. In compulsory systems of normative attraction alternative sexual preferences become illegitimate. Rubin's (1999) conception of the Charmed Circle would place fat admiration as "abnormal" and the "incorrect" way to perform sex. Fat Admirers (FAs) reject compulsory thin desire due to their sexual preferences for fat individuals, ranging in size, shape, and gender identity (Swami and Tovée 2009). 
Previous research posits that stigma can be associated with FAs. Scholars discussing preferences of FAs (Swami and Furnham 2009; Swami and Tovée 2009) understand the spectrum of desire existing within this community, but are less interested in explaining what holding a stigmatized identity means to FAs and Female Fat Admirers (FFAs). The interaction among FAs and the ways in which they create, maintain, and protect their identities is useful in understanding the full impact of stigma in relation to anti-fat bias.

Due to their stigmatized status, some members of the FA community communicate experiences of stigma on an online forum. In-group members of these communities are individuals who identify as FA in opposition to out-group members, or individuals who discriminate against fat admiration. In-group and out-group distinctions represent the intergroup relations of FAs, or, "the formation of functioning within a group of shared perspectives upon certain aspects of social reality" (Tajfel 1982,3). Members of the out-group are individuals who see the in-group as threatening to social mores and disruptive to conventional practices. Fat individuals and other out-group members hold disbelief, incredulity, or hatefulness towards FAs, which contributes to their further stigmatization.

Using an internet ethnography of the FA forum, Dimensions, this research project investigated the stigma FAs face by asking: how they use self-protective strategies against stigma and how does having an FA identity influence interactions about stigma. FAs on the forum employed strategies similar to Crocker and Major's (1989) typology for self-protective buffers. I argue that a fourth buffer exists; dialogic essentialism. Dialogic essentialism describes the process of protecting against stigma for individuals who hold essentialist beliefs about their stigmatized trait in conjunction with strong in-group saliency with similarly stigmatized others. Dialogic essentialism and Crocker and Major's (1989) self-protective strategies help to prevent 
rejection from similar others by boosting members' self-perception and self-esteem when their identity is threatened by the out-group.

\section{Stigma and Social Identity Formation}

Goffman (1963) defines the concept of stigma as the social process in which an individual with a discrediting attribute is ostracized or condemned for their abnormality. Goffman (1959) also created the concept of impression management, or the attempt an individual makes to influence the perception of themselves by others. Stigma and impression management work together in structuring the self-perceptions of individuals, which in turn creates a person's social identity.

Goffman's (1963) idea of "courtesy stigma" suggests that stigma is experienced not only by the individual with a discrediting attribute, but to the people close to the stigmatized person. Hebl and Mannix (2003) illustrated that courtesy stigma is attributed to individuals in mere proximity to a fat person, whether or not an actual relationship between the two existed. People perceived the target of courtesy stigma as maintaining a relationship with a stigmatized person, and, therefore, as having similar, if not the same characteristics. Moreover, the feeling and intensity of stigmatization can vary across different situations. Crocker (1999) defined this concept as "situational stigma," or the unstable distortions of personal characteristics that differ in each immediate social context. Self-worth and self-esteem manifest differently across unique situations, which influence how stigma is experienced.

Logic assumes that stigma from others will lower self-esteem; however researchers have found that not all stigmatized individuals experience a devaluation in their self-conceptions. Stigmatized individuals can experience negative life outcomes and still maintain high levels of self-esteem. Crocker and Major (1989) proposed a theoretical perspective in which self- 
protective strategies buffer against negative consequences of stigma. They maintain that individuals challenge stigma at the interpersonal and group levels using three protective strategies: 1. attributing negative feedback to one's group membership, 2. self-protective properties of in-group comparisons, and 3. selectivity of values as self-protection for the stigmatized.

Crandall et. al $(2000,357)$ stated that use of these strategies is contingent upon the saliency of group membership. Frable et al. (1998) showed that individuals who are aware of similar stigmatized others have higher positive affect and higher self-esteem compared to stigmatized individuals unaware of similar others. In this regard, knowledge of community acceptance is a self-protective strategy against the predominant cultural views attributed to the individual's stigmatized self.

Stigmatization arises from a multitude of discriminatory situations. Essentialist perspectives, or theories that propose biological determinacy for human characteristics (Grzanka, Zeiders, and Miles 2016), express claims of natural constructions of stigmatized traits. Haslam and Levy (2006) examined the relationship between prejudice and essentialist beliefs, hypothesizing seven dimensions of essentialist attitudes: immutability, fixity, discreetness, defining features, historical invariance, universality, and biology. The authors concluded that there are ambiguous implications in reference to features of tolerance in that people hold essentialist beliefs to either condemn or accept stigmatized sexual orientations.

Yost and Hunter (2012) proposed a concept of "socialized essentialism," which refers to external influences that lead participants to the BDSM (bondage, discipline, sadism, and masochism) community; however, over time, these members find that BDSM experiences became an essential part of their sexual identities. This finding relates to McKenna and Bargh's 
(1998) research on internet "newsgroups," which explains how online groups act as virtual communities that impact the identity of members with concealable stigmas. The researchers' concept of "identity demarginalization" emphasizes that higher participation in groups with similar others can lead to active identity change, greater self-acceptance, and an increase in identity importance. These works suggest that identity saliency can change with increased participation in a group, but how members of a "deviant" group protect themselves from further stigmatization is relatively unknown.

With Crandall et al.'s (2000) findings that group saliency is important in the employment of self-protective strategies and McKenna and Bargh's (1998) discussion of identity change, I argue that there is a fourth self-protective strategy against stigma: dialogic essentialism. Dialogic essentialism refers to the strategy members employ when they hold essentialist beliefs about their preferences that become normalized through critical dialogue with similar others. This fourth strategy is contingent upon in-group saliency in order for critical and meaningful dialogue to affect identity formation.

\section{Stigma and Fat Admirers}

While it is clear that fat individuals are stigmatized in Western culture, there has been littler research on the stigma faced by FAs. One of Millman's $(1980,20)$ respondents claimed, "in my opinion, fat admirers have a lot more problems than fat women" (17). Another respondent stated, “it's hard for them [FA's], too. They get asked, 'How could you go out with her? She's so fat.' Or, 'Couldn't you get better than that?' They know what they like, but there's also what society dictates." Millman $(1980,4)$ further wrote that organizations stress "how fat people and fat admirers are victims of prejudice, stigma, and consequent self-hatred," (emphasis added). Goode and Preissler $(1983,200)$ stated, "for the FA, the stigma of obesity represents 
'guilt by association' - or, to be more specific, guilt by preference.” Keeping in mind Goffman's (1963) courtesy stigma, outside others view FAs with the same negative attributes as their love interests.

Scholars have discussed fat admiration in both gay and straight communities, the categorization and preferences of men's practices within fat acceptance organizations, the male gaze, and male FAs as sexual predators (Gimlin 2001; Swami and Furnham 2009; Swami and Tovée 2009; Monaghan 2005; Moskowitz et al 2013; Quidley-Rodriguez and De Santis 2017). However, previous researchers have yet to explore FAs' experiences concerning stigma due to their sexual preferences.

FAs challenge prevailing beliefs about fat women, such as their sexual desperation, their inability to be viewed as sexually desirable, or how "fat women [are treated]....as a protected category incapable of granting sexual consent" (Goode 2002, 531). Other scholars see FAs as sexually predacious and fetishistic, especially when gender inequality is reinforced (Saguy 2002, Colls 2012, White 2016).

Saguy (2002) and Colls (2012) believe that in settings such as the National Association to Advance Fat Acceptance (NAAFA), women's sexual partner selection is limited and the competition for affection places emphasis on the male gaze. Saguy (2002) labeled these circumstances "fat heterosexuality," where sexual partnership resembles thin heterosexual couples with similar gender inequalities. Colls (2012: 32) observed that "fat admiration is complicit in... [the] objectification of 'fat' on women rather than the desire of fat women themselves." White (2016: 969) argued that FAs perpetuate the sexual consumption of women in that they "subvert some norms of sexual attraction, but continue to operate in an economy of desire based on the value (and objectification) of particular body types." These scholars 
disregard FAs who, in the present study, make clear that they do not participate in such harmful fetishistic practices. For example, Dewey, a forum member, wrote "The problem with the word 'fetish' is that it has a lot of unnecessary and negative psychological baggage that doesn't apply to most FAs." Joseph agreed that "fat is a preference... a fetish is something someone needs to have in order to be turned on sexually." These men rejected the label of fetishist and expressed their attraction as a sexual preference. Such dismissal produced stigma and invisibility to the subversive techniques employed by FAs in challenging fat stigma.

Online communities, such as the Dimensions forum, provide a virtual space in which members work to dispel misconceptions of the community that are evident in previous scholarship. By using an internet ethnography, I analyzed the deployment of self-protective strategies to explain how stigmatized FAs discredit other deviant groups, employ impression management skills that ingratiate them from the "bad eggs," and dialogically defend their sexual practices as normal in order to validate their identity. This work provides a deeper understanding of who experiences fat stigma and the ways in which they buffer against these negative feelings.

\section{Methods}

According to Hine (2015), the goal of an internet ethnography is to understand the meaningmaking of participants in a setting where community members' engagement with their computermediated communication can be studied. Similar to traditional ethnographic work, internet ethnographies consist of a field site, field notes, and thick description of findings. Data are readily available information from an online source(s) that is thematically coded to better comprehend a social phenomenon.

The present internet ethnography began in March 2018 after an online search for a fat admiration forum. Dimensions was the most specific website for this query and has been discussed in previous literature on fat admiration (Farrell 2011). Dimensions started as a 
magazine for male FAs. After 1994, the magazine became an online forum, and ended as an inprint magazine in 2004. Dimensions now includes female members, has almost 2 million posts, and over 30,000 members.

Demographics for members are difficult to ascertain; however due to the times in which members post (from mid-morning to late evening) and access to electronic devices, members are most likely working, middle, or upper-class. The majority of usernames and pictures have no indication of the race/ethnicity, age, ability status, gender, class, or sexuality, but the pictures that do exist suggest an overwhelmingly white, cisgender, heterosexual, male population in their 30s40s. ${ }^{1}$

Research was conducted using the "lurker" approach in which I did not create an online account or have direct involvement with community members. This methodology is similar to Davenport et al. (2019) who thematically analyzed discourse on fat acceptance blogs without explicit consent from participants. ${ }^{2}$ To ensure confidentiality and privacy for members (Im and Chee 2006), usernames were changed to pseudonyms using a random name generator. Randomly selected pseudonyms provide no indication of personal information as they are not derived from usernames. Due to a lack of identifiable features from usernames, photos, and the confidentiality

\footnotetext{
${ }^{1}$ I do caution readers about assuming homogeneity within this community (Pausé 2014).There are individuals who are FAs/FFAs <Fat Admirers, Female Fat Admirers $>$ and also identify as fat. These narratives illustrate the nuances of being fat and admiring fatness. Elsie stated "I already feel better about myself. Knowing that I'm not alone as a BMH/FFA <Big Handsome Man/Female Fat Admirer> and being a BBW $<$ Big Beautiful Women>." Contrarily, Kelly wrote "I feel marginalized because I'm a BBW <Big Beautiful Woman> that is attracted to BHM <Big Handsome Men>..."

${ }^{2}$ McKee and Porter (2008), Boellstoff et al. (2012), and Flicker et al. (2004) suggested that researchers who study virtual spaces must consider ethical concerns in advance. Eynon et al. $(2012,286)$ stated that "if the data is not controversial, or if anonymity can be ensured, then this [confidentiality] is less of a concern compared to controversial research topics..." Davenport et al. $(2019,281)$ stated that sites are public if they do not require membership, passwords, or are blocked by a search engine. Because data are publicly available and Institutional Review Board (IRB) approval was granted, this research project followed ethical guidelines.
} 
measures in creating pseudonyms, anyone visiting the website would not be able to recognize members unless they become members themselves, which is why the forum name is not anonymous.

I became immersed in the forum site with preliminary findings of stigma as a theme for both FAs and the fat individuals they admire. Immersion into the site began in February 2018. I spent a month regularly visiting the site to take notes of ongoing conversations and information about the forum. Data were collected and analyzed from March-October 2018 from four different threads. Three threads were located on the FA/FFA forum and one on the BHM/FFA forum. Each chosen thread contained at least fifty responses and over five-thousand views to ensure relatively frequent participation. Threads were chosen by title and response/view requirements that emphasize issues within the FA community. No time limits were set for analyzing posts because discussions were led for years with active participation throughout. Selected posts were printed in chronological order and analyzed line-by-line. A total of seven hundred and seventyseven posts were analyzed. Links to other sites or pictures were NOT included.

Field notes were entry dates and times of posts and analytic coding of posts with a three to ten-word summary. Field notes highlighted posts that were eloquent descriptions of the thread itself, conversations that included argumentative language, and arrows to indicate the flow of conversation between members. After highlighting posts from all four threads, I created a summary page of each thread with the main theme and the role of stigma. Field notes were reviewed multiple times over the course of analysis and final analysis used an iterative process to identify which self-protective strategy and emergent themes posts were part of (Neale 2016, 1098).

\section{A Constellation of Strategies}


FAs experienced stigma, which is due to lack of understanding or explicit contempt of their sexual preferences. Forum members explained out-group members' prejudiced attitudes as the reason for why stigma exists for their community. Crocker and Major $(1989,612)$ called this outgroup versus in-group comparison as “attributing negative feedback to prejudice against one's group membership.” For example, Glen summarized prejudice against FAs: “The main problem in society's view of fat people, and the mainstream's contempt for FAs is just collateral damage. If you believe that fat people are inherently unhealthy and unattractive (i.e., if you're a bigot), then you pretty much have to believe there's something wrong with anyone who is attracted to them." In this post, Glen revealed the out-group perspective that legitimated the stigmatization against FAs while simultaneously attacking people who believed that fat individuals are undesirable. Cameron commented, “don't discount that all the prejudices against fat people also relate to the FA...Remember we constantly get thrown at us 'how can you in good conscious be attracted to someone in an inherently unhealthy state."' This statement is an echo of Millman's (1980) earlier findings of incredulity by non-FAs who questioned the sanity of FAs in their rejection of a thin partner. The concept of Goffman's courtesy stigma also resonated with Cameron's post in that stereotypes of fat individuals are often transferred onto the FA who is desiring them.

The second self-protective strategy, "comparing outcomes with those of the in-group rather than the advantaged outgroup," (Crocker and Major 1989, 614) described FAs' knowledge of their stigmatization that led members to create divisions within the forum. Member-tomember comparisons explained "there is nothing wrong with having a predilection for dating whomever you want as long as it's not a kid," (Joseph). In this post, Joseph stated that being an FA is not fetishistic and that sexual preferences should not be stigmatized, unless they are for 
pedophilia. Greg replied “or your own family member.” These statements illustrated what Goffman $(1963,108)$ described as common among stigmatized groups: "the phrase "concern with in-group purification' is used to describe the efforts of stigmatized persons not only to 'normify' their own conduct but also to clean up the conduct of others in the group." In shifting negative attention from the identity of an FA to something seemingly worse, these men used negative stereotypes of pedophilia and incest to affirm their identities while also employing impression management techniques to define FAs as less harmful than other groups.

The third strategy proposed by Crocker and Major $(1989,616)$ is the devaluation of the “negative dimensions of in-group and valuing positive dimensions of in-group" behaviors. Devaluation in this sense does not mean the complete rejection of negative elements of the community. Members often referred to negative aspects of the FA community but felt strong attachment to the community nonetheless. Kayla stated, “...I know that I'm not alone, and that I am understood. That I am not a freak or a horrible person... when I need to reconnect with my FFA desires and to affirm their validity, I come back here, and am once again treated like family." Validation and legitimacy of an FA identity as well as the space in which members can meet others who admire them represented the inclusion and positivity that resulted from in-group membership.

\section{A Narration of Immutability}

Crocker and Major's (1989) work described important strategies against stigma that apply to FAs; however, focusing on an individual's perception of their attachment to the group and why they are part of a specific group led to uncovering a key element to protective steps against stigma that is missing in current academic discussions. 
Dialogic essentialism explains how group membership and essentializing arguments buffer against the internalization of stigma. Dialogic essentialism draws from Bakhtin's (1981) literary theory of the novel as a new genre that is transformed through limitless interactions with other genres. Dialogic refers to individuals' limitless interaction with others in their social world. As Crossley $(2006,89)$ argued: "Our relations with others are dialogical and the culture into which we are socialized involves 'tools' of argument, alongside prescribed norms and values tools which we can appropriate and use to challenge those norms and ideals if, and to the extent that, we disagree with them." Dialogue expands our understanding of norms and empowers agents to subvert or uphold cultural standards in an unbounded manner. Through interaction, people come to believe that their attraction to fat people is an inherent and immutable part of their personhood.

Comparisons, interactions, and communication enable individuals to become aware of and challenge perceptions of the self. Dialogic essentialism describes the importance of dialogue with other stigmatized group members by allowing potential innovation in identification with essentialist arguments to occur. Dialogic essentialism emphasized both group cohesion and essentialist beliefs that protected member's self-esteem when criticized about their seemingly aberrant identities.

Evidence of essentialist arguments from the forum suggested that FAs understood their sexual preference as an immutable love for fat individuals, not a love of individuals who happened to be fat. Bobby stated that he was "wired to liking fat girls and it'll never go away." Molly echoed this statement, "everyone is hard-wired to be attracted to something." Being wired, or programmed to a specific preference, denoted a commonality among in-group members. It also presumed that members had no choice in admiring fat bodies. Harvey argued, "you can't 
fight nature. Nature has proven time and time again to me that Big Girls is where its [sic] at for me." Attributing his discrediting trait to something beyond his control, Harvey rejected the possibility that his love of fat women deserved admonition and thereby diminished his feelings of deviance. Denying responsibility for their preference involved using essentialist arguments and interactions with others who believed in or identified as an FA.

Examples of hard-wired identities illustrated the inability to change who one is attracted to. Nannie posted, 'I’ve been attracted to larger men since I was in middle school. I finally accepted that it was apart [sic] of who I was just recently...I am so thankful to find a place where I can talk to people who are going through what I'm going through.” Natasha wrote, "When I first stumbled on Dimensions it meant I wasn't alone. It meant there wasn't something wrong with me when I got butterflies in my stomach everytime [sic] a handsome $400 \mathrm{lb}$ guy crossed my path." Expressing these feelings of shame is only one step in dialogic essentialism. Critical conversation with similar others alleviated feelings of stigma, but strong ties to the in-group made these dialogues salient to members.

Only within a dialogic exchange - where multiple voices confirm a blemished identity and innovative ways to cope with that identity - can members internalize acceptance received from being part of a stigmatized population. Textual representations of essentialist attitudes fortified the connection among members and the conviction they felt towards their identity. Public dialogue normalized preferences and linked individuals to a community to help buffer against stigma. This process in turn strengthened members' identification with the in-group and consolidated a shared essentializing attitude despite the heterogeneous narration of fat admiration. 
Reconfiguring their exclusion from standards of compulsory thin desire, FAs justified their rejection of norms through descriptions of unalterable, immutable attraction to fat individuals. Proclamations of intrinsic aspects of FA subjectivity allowed members to subvert compulsory norms of desire and constructed a space which challenged anti-fat discourse.

Disavowal of abnormality became central to the group's processes such that members invariably promoted validation and acceptance when stigmatization was perceived.

Yost and Hunter's (2012) findings confirmed that individuals who joined groups espousing essentialist beliefs held sexual identities greatly influenced by participation within the group. For FAs, narrations of immutability allowed members to publicize their innate admiration for "undesirable" groups. Community saliency enabled members to feel less deviant through markers of acceptance that legitimated feelings of desire and strengthened self-perception and self-esteem.

\section{Discussion}

Dialogic essentialism is a self-protective strategy that illustrates how engaging in critical dialogue with similar others buffers against feelings of stigmatization when in-group saliency is present. Dialogic essentialism is similar to sexual racism (racial favoritism in romantic relationships) in that sexual desire is described as not a preference, but a biologic force (Bedi 2015; Callander et al. 2015; Robinson 2015; Jones 2020). Sexual racism and fat admiration are two illustrations of sexual preferences that have become acceptable practices for exclusion of certain groups.

For the FA, rejecting compulsory thin desire may help to advance the fat acceptance movement. Masada $(2015,204)$ wrote: "We need to talk about how fatness and fat admiration function as forms of queerness, of transgression...We need to talk about problematic, abusive, 
and oppressive expressions of fat admiration/appreciation/sexuality." This quote calls for conversations about loving fatness, dialogues currently taking place in the FA community where members seek to empower their sexual partners. Offering new ways to perform fat sex, fat embodiment, and equality in sexual relationships can help shape straight and gay (Bear) sexualities among individuals who valorize larger bodies (Hennen 2005; Afful and Ricciardelli 2015). Fat admiration has the potential to change discourses of desire by transgressing against the standards of thin attraction that lends to a critique of normative sexual practices.

Considering FAs' voices in the fat acceptance movement can help to reimagine fat sex while also challenging social inequality for those deemed abnormal due either to size or sexual preference. Fat admiration has historically been seen as oppressive and problematic, yet without the voices of FAs, such negative assumptions from outside others obstruct the transgressive nature of admiring fatness and the stigma associated with an FA identity.

\section{Declaration of Interest}

There is no potential conflict of interest. 


\section{References}

Afful, Adwoa A. and Rose Ricciardelli. 2015. "Shaping the Online Fat Acceptance Movement: Talking about Body Image and Beauty Standards.” Journal of Gender Studies 24 (4): 453-472.

Bakhtin, M.M. 1981. The Dialogic Imagination. Austin, TX: University of Texas Press.

Bedi, Sonu. 2015. "Sexual Racism: Intimacy as a Matter of Justice." The Journal of Politics 77 (4): 998-1011.

Boellstroff, Tom, Bonnie Nardi, Celia Pearce, and T.L. Taylor. 2012. Ethnography and Virtual Worlds: A Handbook of Method. Princeton University Press: Princeton: NJ.

Callander, Denton, Christy Newman, and Martin Holt. 2015. "Is Sexual Racism Really Racism? Distinguishing Attitudes Toward Sexual Racism and Generic Racism Among Gay and Bisexual Men." Archives of Sexual Behavior 44 (7): 1991-2000.

Colls, Rachel. 2012. "Big Girls Having Fun: Reflections on a 'Fat Accepting Space."” Somatechnics 8 (1): 18-37.

Crandall, Christian, Jo-Ann Tsang, Richard Harvey, and Britt Thomas. 2000. "Group IdentityBased Self-Protective Strategies: The Stigma of Race, Gender, and Garlic.” European Journal of Social Psychology 30 (3): 355-381.

Crocker, Jennifer. 1999. "Social Stigma and Self-Esteem: Situational Construction of SelfWorth.” Journal of Experimental Social Psychology 35 (1): 89-107.

Crocker, Jennifer and Brenda Major. 1989. "Social Stigma and Self-Esteem: The Self-Protective Properties of Stigma." Psychological Review 96 (4): 608-630.

Crossley, Nick. 2006. Reflexive Embodiment in Contemporary Society. Open University Press: New York, NY.

Davenport, Kate, Wendy Solomons, Sylvia Puchalska, and Joanne McDowell. 2019. "Size Acceptance: A Discursive Analysis of Online Blogs. Fat Studies 7 (3): 278-293."

Eynon, Rebecca, Jenny Fry, and Ralph Schroeder. 2012. “The Ethics of Internet Research.” In SAGE Internet Research Methods. Pp 279- 304. Ed. Jason Hughes. Sage Publications: Thousand Oaks, CA.

Flicker, Sarah, Dave Haans, and Harvey Skinner. 2004. "Ethical Dilemmas in Research on Internet Communities." Qualitative Health Research 14 (1): 124-134. 
Farrell, Amy. 2011. "Fat Shame: Stigma and the Fat Body in American Culture." New York, NY: New York University Press.

Frable, Deborrah E. S., Linda Platt, and Steve Hoey. 1998. "Concealable Stigma and Positive Self-Perceptions: Feeling Better Around Similar Others.” Journal of Personality and Social Psychology 74 (4): 909.922.

Gimlin, Debra L. 2001. "Body Work: Beauty and Self-Image in American Culture.” Berkeley, CA: University of California Press.

Goffman, Erving. 1959. The Presentation of Self in Everyday Life. Doubleday: Oxford, England.

Goffman, Erving. 1963. Stigma: Notes on the Management of a Spoiled Identity. Englewood Cliffs, N.J., Prentice-Hall.

Goode, Erich. 2002. "Sexual Involvement and Social Research in a Fat Civil Rights Organization.” Qualitative Sociology 25(4):501-534.

Goode, Erich, and Joanne Preissler. 1983. "The Fat Admirer.” Deviant Behavior 4: 175-202.

Grzanka, Patrick R., Katherine H. Zeiders, and Joseph R. Miles. 2016. "Beyond "Born This Way?" Reconsidering Sexual Orientation Beliefs and Attitudes." Journal of Counseling Psychology 63 (1): 67-75.

Haslam, Nick and Sheri R. Levy. 2006. "Essentialist Beliefs About Homosexuality: Structure and Implications for Prejudice." Personality and Social Psychology Bulletin 32 (4): 471485 .

Hebl, Michelle R. and Laura M. Mannix. 2003. "The Weight of Obesity in Evaluating Others: A Mere Proximity Effect." Personality and Social Psychology Bulletin 29(1): 28-38.

Hennen, Peter. 2005. "Bear Bodies, Bear Masculinity Recuperation, Resistance, or Retreat?" Gender and Society 19 (1): 25-43.

Hine, Christine. 2015. "Ethnography for the Internet: Embedded, Embodied, and Everyday." London, England: Bloomsbury Publishing PLC.

Im, Eun-Ok, and Wonshik Chee. 2006. "An Online Forum as a Qualitative Research Method: Practical Issues.” Nursing Research 55 (4): 267-273.

Jones, Angela. 2020. Camming: Money, Power, and Pleasure in the Sex Work Industry. New York University Press: New York, NY.

Masada, Mycroft. 2015. “Good News: A Sermon on Fat Justice.” Fat Studies 4 (2): 197-207. 
McKee, Heidi, and James E. Porter. 2008. "The Ethics of Digital Writing Research: A Rhetorical Approach." National Council of Teachers of English 59 (4): 711-749.

McKenna, Katelyn Y.A. and John A. Bargh. 1998. "Coming Out in the Age of the Internet: Identity 'Demarginalization' Through Virtual Group Participations.” Journal of Personality and Social Psychology 75 (3): 681-694.

McRuer, Robert. 2014. “Compulsory Able-Bodiedness and Queer/Disabled Existence.” Pp 369378 in The Disability Studies Reader Ed. Lennard J. Davis. Routledge: New York, NY.

Millman, Marcia. 1980. Such a Pretty Face: Being Fat in America. New York, NY: Norton.

Monaghan, Lee E. 2005. "Big Handsome Men, Bears and Others: Virtual Constructions of 'Fat Male Embodiment." Body and Society 11 (2): 81-111.

Moskowitz, David A., Jonathan Turrubiates, Hector Lozano, and Christopher Hajek. 2013. "Physical, Behavioral and Psychological Traits of Gay Men Identifying as Bears." Archives of Sexual Behavior 42: 775-784.

Neale, Joanne. 2016. "Iterative Categorization (IC): A Systematic Technique for Analyzing Qualitative Data.” Addiction 111 (6): 1096-1106.

Pausé, Cat. 2014. "X-Static Process: Intersectionality Within the Field of Fat Studies.” Fat Studies 3 (2): 80-85.

Puhl, Rebecca, and Kelly D. Brownell, 2001. "Bias, Discrimination, and Obesity." Obesity Research 9 (12): 788-805.

Puhl, Rebecca M, and Kelly D Brownell. 2006. "Confronting and Coping with Weight Stigma: An Investigation of Overweight and Obese Adults." Obesity 14 (10): 1802-1815.

Quidley-Rodriguez, Narciso, and Joseph P. De Santis. 2017. "A Concept Analysis of Bear Identity." Journal of Homosexuality 16: 1-17.

Rich, Adrienne. 1980. “Compulsory Heterosexuality and Lesbian Existence.” Signs 5 (4): 631 660.

Robinson, Brandon A. 2015. “'Personal Preference' as the New Racism: Gay Desire and Racial Cleansing in Cyberspace." Sociology of Race and Ethnicity 1 (2): 317-330.

Rubin, Gayle. 1999. "Thinking Sex: Notes for a Radical Theory of the Politics of Sexuality." Pp 143-178 in Culture, Society and Sexuality A Reader eds. Richard Parker and Peter Aggleton. UCL Press: London, UK.

Saguy, Abigail. 2002. "Sex, Inequality, and Ethnography: Response to Erich Goode." Qualitative Sociology 25: 549-556. 
Swami, Viren, and Adrian Furnham. 2009. "Big and Beautiful: Attractiveness and Health Ratings of the Female Body by Male "Fat Admirers."' Archives of Sexual Behavior 38: 201-208.

Swami, Viren, and Martin J. Tovée. 2009. "Big Beautiful Women: The Body Size Preferences of Male Fat Admirers." Journal of Sex Research 46 (1): 89-96.

Tajfel, Henri. 1982. "Introduction." 1-11. In Social Identity and Intergroup Relations, edited by Henri Tajfel. Cambridge, England. Cambridge University Press.

White, Francis Ray. 2016. "Fucking Failures: The Future of Fat Sex.” Sexualities 19 (8) 962979.

Yost, Megan R. and L.E. Hunter. 2012. "BDSM Practitioners' Understandings of Their Initial Attraction to BDSM Sexuality: Essentialist and Constructionist Narratives." Psychology and Sexuality 3 (3): 244-259. 